\title{
Bioremediation of Nitro-aromatics: An Overview
}

\author{
N.S. Kasture \\ Assistant Professor, Department of Microbiology, Siddharth College, Jafrabad, Dist. Jalna (M.S.), India
}

\begin{abstract}
Since last two three decades due to industrialization, globalization there is tremendous change in human life that means to fulfil the need various industries are flourishing. We are facing the problem of environmental pollution and also facing hazards to biodiversity. So it becomes our duties to remediate the environment by using scientific tool like bioremediation. This is emerging as an effective innovative technology for treatment of a wide variety of contaminants. Bioremediation involves various approaches like phytoremediation (plants) and rhizoremediation (plant and microbe interaction). Bioremediation is most effective technology for treatment of soil and water which are mostly contaminated by human activities. It is an economical process that means operation cost is less. In current review contamination of water and soil by nitroaromatic compounds and the role of bacteria and fungi and their enzyme activity to enhance bioremediation process is studied by literature review. Nitro-aromatic compounds are used worldwide as explosives, pesticides and as a feedstock for the manufacture of many products, including dyes, pharmaceuticals, fungicides and plastics. On the contrary, nitro-aromatic compounds are released into the biosphere exclusively from the anthropogenic sources. Nitro-aromatic compounds do not only come from manmade sources; they also are formed by some natural processes, such as photochemical reactions in the atmosphere. Extensive production and indiscriminate application of nitro-aromatic has led to environmental pollution. Hence, nitro-aromatic compounds are recognized as Hazardous Rating-3.
\end{abstract}

Keywords- Bioremediation, enzyme, nitro-aromatic compounds, phytoremediation, rhizoremediation.

\section{INTRODUCTION}

One of the major environmental problems examined by the world today is the contamination of soil, water and air by toxic chemicals. Eighty billion pounds of hazardous organopollutants are produced annually and only $10 \%$ of these are disposed of safely. The estimated for their decontamination using traditional approaches such as incineration and landfilling is approximately one trillion [1]. Nitro-aromatic compounds are toxic to plant, animal and human health and poses significant health and environmental risk due to its mutagenic and carcinogen activity. Nitro-aromatic compounds are generally considered to be highly resistant to microbial degradation. The purification of wastewater contaminated with these pollutants is very difficult since they are resistant to the conventional treatment techniques. Although several investigators have used physical and chemical methods such as volatilization, photodegradation, photo-catalysis and advanced oxidation to treat the wastewater containing nitro-aromatic compounds.

\subsection{Bioremediation: a brief introduction}

The term bioremediation was firstly introduced by scientists in early 1980s. Bioremediation is the use of the living organism to reduce or eliminate environmental pollution by various hazardous chemicals. Bioremediation involves transformation of complex or simple chemical compounds into nonhazardous forms by microbes [2]. The past two decades have seen a tremendous upsurge in the search for cost-effective and environmentally benign alternatives to the conventional methods for remediation of hazardous wastes. The use of microbes to clean up polluted environments is a rapidly changing and escalating area of environmental biotechnology. The explanation for their remarkable range of degradative abilities is that, by the time human beings came on the scene, microbes had already coexisted for billions of years with an immense variety of pollutants. The vast diversity of potential substrates for growth led to the evolution of enzyme capable of transforming many unrelated natural pollutants by many different catalytic mechanisms. The resulting giant 'library' of microbial enzymes serves as raw material for further revolution whenever a new chemical becomes available [3].Being eco-friendly, this mode is sustainable too. The general approaches to bioremediation are basically (i) intrinsic bioremediation, (ii) biostimulation and (iii) bioaugmentation.

\section{NITRO-PHENOLS: A BRIEF ACCOUNT}

Nitro-phenols (NPs) are among the most important and versatile industrial organic compounds with applications as ingredients in pesticides, pharmaceuticals, pigments, dyes, and rubber chemicals [4]. Among the mononitrophenols, $p$-nitrophenol (PNP, also known as 4- 
nitrophnol or 4-NP), is the most common and important in terms of quantities manufactured and extent of environmental contamination. PNP is (i) used for synthesis of medicines, dyes, explosives, leather colouring, wood preservatives, and rubber chemicals [5] and (ii) generated during formulation, distribution, and field application of pesticides or photodegradation of pesticides that contain the nitro-phenol moiety [6]. Consequently, PNP has often been detected in wastewater, rivers, soils, and ground water. Most nitrophenols, including PNP and 3-nitrophenol, enter the environment through manufacturing and processing. Nitro-phenols are toxic to plants, microorganisms, animals and humans [7, 8]. The US EPA (1980) lists $p$ nitrophenol and 2-nitrophenol as priority pollutants, and restricts their concentrations in natural waters to $10 \mathrm{ngL}$ ${ }^{1}[9]$. The presence of substituted groups, i.e., nitro- and chloro-, on phenols increases the toxic effects on ecosystem and human health due to their persistence in the environment. Most of these compounds are resistant to microbial degradation, especially at high concentrations.

\section{$2.1 p$-nitrophenol(PNP)}

$p$-nitrophenol (PNP), a priority environmental pollutant, occurs in industrial effluents posing esthetic and health problems [10] .p-nitrophenol (PNP) was first registered in the United States in 1963 for use as a fungicide to control fungal mold on leather. In 1980, its application was registered for the protection of leather and military products at a concentration of $0.7 \%$ of dry leather weight. Its use was further extended for treatment of cork used in missile silo construction $[11,12]$. It is primarily used as (i) solvent, (ii) commodity chemical for the synthesis of azo and sulphur dyes, (iii) explosives, (iv) number of intermediates, (v) pesticides (parathion, methyl parathion),(vi) insecticides (carbofuran, phosphalon, flurodifer), (vii) herbicides ( nitrofen, bifernose), (viii) tubercutostatic 4-aminosalycilic acid, (ix) analgesic (4acetoaminophenol/ paracetamol). PNP is manufactured on large scale (20 million $\mathrm{Kg}$ per annum) by many companies from Europe, USA and Japan. In 1996, environmental release of PNP as reported by USA manufacture was 45-450 MT per year. Its hazardous consequences are summarized in Table 1.

\subsubsection{Toxicity}

$p$-nitrophenol is a corrosive eye irritant (Toxicity Category I, indicating the greatest degree of acute toxicity) and a potential dermal irritant.p-nitrophenol is acutely toxic (Toxicity Category II) via the oral route and moderately toxic (Toxicity Category III) via the dermal route.

A subchronic oral toxicity study in rats showed an increased incidence of acute mortality, while a dermal study in mice resulted in dermal irritation and mortality. Chronic toxicity has not been conclusively evaluated. $p$ nitrophenol has been classified as Group D for carcinogenicity, indicating that there is inadequate information to determine its cancer potential. $p$ nitrophenol is not believed to cause reproductive or developmental toxicity, but additional studies are needed to confirm these tentative findings [12].

Since $p$-nitrophenol is classified as Toxicity Category I for eye irritation potential and since data on skin irritation potential are not available, the Agency is imposing risk reduction measures including use of personal protective equipment (chemical-resistant gloves and apron, and protective eyewear) as well as a long sleeved shirt, long pants, shoes and socks [12].

\section{BIOLOGICAL SOLUTION TO THE POLLUTION}

Nitro-aromatic compounds, now a days are recognized as high risk contaminants. Hence, their removal from environment is the first priority. Chemical approach may offer a temporary solution and may pose environment threat. On the contrary, microbial system is ubiquitous and versatile. It is well known that microbial entity plays central role in nutrient cycling on this planet [13]. Current routes for amelioration therefore, employ microorganisms which either immobilize or transform contaminants to innocuous end products. The incredible metabolic versality of microbes permits them to (i) inhabit in hostile ecological niches and (ii) exploit compounds as a source of carbon, nitrogen and energy. Such microbial metabolic potential must be harnessed to develop process (es) for detoxification of recalcitrant(s). The strategy [14] offers many advantages like

Table.1: Hazardous consequences of nitro-aromatic compounds [15]

\begin{tabular}{llll}
\hline F-hazard/Exposure & Acute hazard/Symptoms & Prevention & $\begin{array}{l}\text { First Aid/Fire } \\
\text { Fighting }\end{array}$ \\
\hline 1. Fire & Combustible & $\begin{array}{l}\text { No open flames, no } \\
\text { contact with } \\
\text { oxidant. }\end{array}$ & $\begin{array}{l}\text { Powder, water spray, } \\
\text { foam, carbon dioxide. }\end{array}$ \\
2. Explosion & Risk of Fire and explosion on & $\begin{array}{l}\text { Deposition of dust, } \\
\text { close system, dust }\end{array}$ & $\begin{array}{l}\text { In case of fire: keep } \\
\text { drums etc. cool by }\end{array}$
\end{tabular}




\section{Exposure}

4. Inhalation

5.Skin

6. Eyes Redness, Pain.

7. Ingestion

8. Spoilage disposal sea inhalation) explosion. Proof

electrical equipment

and lightening.

Prevent dispersion

of dust! Strict

hygiene

Blue lips/fingers, nails, blue skin, Local exhaust or cough. Burning sensation, confusion, convulsion, dizziness, headache, nausea, sore throat, unconsciousness, weakness.

May be absorbed, redness( further

breathing

protection.

spraying with water.

Protective gloves, protective clothing.

Safety spectacles
face shield or eye
protection in
combination with
breathing
protection.
Do not eat, drink or
smoke during work.

Safety spectacles face shield or eye protection in combination with breathing protection.

Abdominal pain, sore throat, vomiting (sea inhalation)

smoke during work.
Fresh air, rest, refer for medical attention, artificial respiration may be needed.

Remove contaminated clothes. Rinse and then wash skin with water and soap. Refer for medical attention. First rinse with plenty minutes (remove contact lenses if easily possible), then take to a doctor.

Rinse mouth, rest refer for medical attention. of water for several
Operability in situ (ii) permanent elimination of contaminants through either biochemical transformation or cometabolic or mineralization, (iii) avoiding harsh physical and chemical treatment(s), (iv) cost effectiveness and (v) more public acceptability.

\subsection{Bacteria}

Microbial degradation of $p$-nitrophenol has been described for several genera including Flavobacterium, Pseudomonas, Moraxella, Arthrobacter and Bacillus [16]. Bacillus sphaericus, isolated from an agricultural soil by selective enrichment, transform $p$-nitrophenol [17]. A strain of Pseudomonas putida was found to degrade $p$ nitrophenol as a sole source of carbon, nitrogen and energy [18]. Pseudomonas sp and Rhodococcusopacus can utilize $p$-nitrophenol as a sole source of carbon and energy [19]. Rhodococcuswratislaviensis strain capable of utilizing $p$-nitrophenol as the sole source of carbon and energy and release the nitro group from the compound as nitrite. The nitro group of PNP enhances the resistance of the aromatic ring to biodegradation, bacterial strains able to utilize PNP as a sole carbon and nitrogen sources include species of Bacillus [19], Burkholderia[20] andSphingomonas sp. and Sphingomonaschlorophenolica strains can transform $p$-nitrophenol [21].

\subsection{Fungi}

Fungi have been used from fermentation of foods to production of pharmaceuticals. Fungi thrive well in inhospitable habitats with environmental extremes because of their enzyme system [22]. Fungi are involved in the biodegradation of undesirable materials or compounds and convert them into harmless, tolerable or useful products. Many organisms are involved in the biodegradation of organic waste, which has resulted in the production of novel substances of biotechnological importance. 
Fungi are recognized for their superior aptitudes to produce a large variety of extracellular proteins, organic acids and other metabolites, and for their capacities to adapt to severe environmental constraints [23]. Fungi not only produce various metabolites like citric acid, homogeneous proteins, heterogeneous proteins, peroxidases but have shown their effectiveness for removal, reduction and detoxification of industrial effluents ingredients. Therefore, an attempt has been made to bring out the capabilities of fungi for bioremediationof industrial effluents. [24] have used filamentous soil fungi like Aspergillus terreus,Cladosporiumcladosporioides, Fusarium oxysporium, Gliocladiumroseum, Penicilliumspp. and Trichoderma koningii isolated from industrially polluted sediments for the removal of Cadmium. The fungus Penicilliumfrequentans has been found to effectively remove phenanthrene in soil [25].

Fungi especially the white-rot fungi produce enzymes viz. laccase, Manganese peroxidase $(\mathrm{MnP})$ and lignin peroxidase (LiP), which are involved in degradation of lignin in their natural lignocellulosic substrates. This ligninolytic system of white rot fungi is directly involved in the degradation of various xenobiotic compounds and dyes. The ability of the white rot fungi to degrade dye can be directly correlated with its ability to degrade lignin; the dye molecules are degraded along with lignin. Use of white rot fungi is the most unique technology of bioremediation as their ability to degrade structurally diverse xenobiotic organopollutants is more [26].

\subsection{Fungi in biodegradation of pollutants}

Biodegradation is an application of biological processes to the treatment of pollution. Most research within the field of bioremediation has focused on bacteria, with fungal bioremediation (mycoremediation) attracting interest just within the past two decades. White rot fungi is a physiological grouping of fungi that can degrade lignin (and lignin- like substances). Four main genera of fungi haveshown potential for bioremediation Phanerochaete, Trametes, Bjerkandera andPleurotus [27]. These fungi cannot use lignin as a source of energy, and instead requiresubstrates such as cellulose or other carbon sources. Thus, carbon sources such as corncobs, straw, and sawdust can be easily used to enhance degradation rates by these organisms at polluted sites. Also, thebranching, filamentous mode of fungal growth allows for more efficient colonization and exploration of contaminated soil.

\subsection{Fungal mechanism of biodegradation}

The main mechanism of biodegradation employed by this group of fungi, however, is the lignin degradationsystem of enzymes. These extracellular ligninmodifying enzymes (LMEs) have very low substrate specificity so they are able to mineralize a wide range of highly recalcitrant organopollutants that are structurally similar to lignin [28]. The fact that these fungal enzymes work extracellularly allows them to access many of the nonpolar, non-soluble toxic compounds that intracellularprocesses (such as cytochrome P450) cannot [29].

\section{CONCLUSION}

This review focuses on various features in bioremediation processes and how the process is acts as biological tool for remediation ofenvironment. It also encompasses the role of bacteria and fungi, their enzymatic activities. Advances in biotechnology, bioremediation has becomes rapidly growing area. Selection of most appropriate strategy to treat hazardous chemicals and contaminated sites by microbial action is still needed.

\section{REFERENCES}

[1] Reddy, C.A. and Mathew, Z. (2001). Bioremediation potential of white rot fungi.Fungi in bioremediation.Gadd, G.M. Cambridge University Press. Cambridge, U.K.

[2] Grady, F. (1985) Biodegradation. Its measurement and microbiological basis.Biotechnol.Bioeng. 27: 660-671.

[3] Ellis, B.M.L. (2000) Environmental biotechnology informatics. Curr.Opin.Biotechnol. 11:232-235.

[4] Haghighi-Podeh, M.R. and Bhattacharya, S.K. (1996) Fate and toxic effects of nitrophenols on anaerobic treatment systems. Water Sci. Technol. 34, 345-350.

[5] Uberio, V. and Bhattacharya, S.K. (1997) Toxicity and degradability of nitrophenols in anaerobic systems. Water Environ. Res., 69, 146-156.

[6] US EPA, (1980) Ambient water quality criteria for nitro-phenols. EPA-440/ s-80-063.

[7] ATSDR (Agency for Toxic Substances and Disease Registry) (1992) Toxicological Profile for Nitrophenols: 2-nitrophenol and 4-nitrophenol Agency for Toxic Substances and Disease Registry (ATSDR). US Department of Health and Human Services, Public Health Service, Atlanta, GA.

[8] Bruning, T., Chronz, C., Their, R., Havelka, J., Ko, Y., Bolt, H.M., (1999) Occurrence of urinary tract tumors in miners highly exposed to dinitrotoluene. Occu Environ Med., 41, 144-149.

[9] Eckenfelder, W.W. (1989) Industrial Water Pollution Control. McGraw- Hill, New York.

[10] Bruhn, C., Lenke, H. and Knackmass, H.J. (1987) Nitrosubstituted aromatic compounds as nitrogen 
source for bacteria .Appl. Environ. Microbiol., 53:208-210.

[11] Verschueren, K. (1996) Handbook of environmental data on organic chemicals ( $\left.3^{\text {rd }} \mathrm{edn}\right)$, Van Nostrand Reinhold Thompson Publ. Co., New York, pp1399-1403.

[12] U.S. Environmental Protection Agency (1998) Test methods for evaluating solid waste. SW-846.3rd edn.

[13]Ehrlich, H. L., (1995) Geomicrobioloy, $3^{\text {rd }}$ edn.Marcel Dekker,Inc.,New York.

[14] Soccol, C.R., Vandenberghe, L.P.S., Woiciechoaski, A.L., Thomaz-Soccol, V.T., Correia, C.T. and Pandey, A. (2003) Bioremediation: an important alternative for soil and industrial waste clean-up. Indian J. Exptl. Biol. 41:1030-1045.

[15] Vidali, M. (2001) Bioremediation: A Overview, Pure Appl. Che. Vol. 73, 1163-1172.

[16] Hanne, L.F., Kirk, L.L., Appel, S.M.,Narayan, A.D.andBains, K.K., (1993) Degradation and induction specificity in actinomycetes that degrade p-nitrophenol, Appl. Environ. Microbiol., 59:35053508.

[17] Kadiyala, V., Smetes, B.F., Chandran, K., Spain, J.C. (1998) High affinity p-nitrophenol oxidation by Bacillus sphaericus .JS905, FEMS Microbiol. Letts., 166:115-120.

[18] Kulkarni, M. (2005) Bioremediation of nitroaromatic compound (p-nitrophenol). Ph.D Thesis, North Maharashtra University, India.

[19] Shinozaki, Y., Kimura, N. and Nakahara, T. (2002) Difference in degrading $p$-nitrophenol between indigenous bacteria in reactor. J. Biosci. Bioengg. 5: 512-514.

[20] Chauhan, A., Samanta, S.K. and Jain, R.K., (2000b) Degradation of 4-nitrocatechol by Burkholderiacepacia: a plasmid-encoded novel pathway.J. Appl .Microbiol., 88:764-772.

[21]Leung, K.T., Tresse,O., Errampalli, D., Lee, H. and Trevors, J. T.(1997) Mineralization of p-nitrophenol by pentachlorophenol-degrading Sphingomonas sp. FEMS Microbiol. Letts., 155:107-114.

[22] Cooke, W.B. (1979) The Ecology of Fungi. CRE Press Inc.,Boca Raton, Floida.

[23]Lilly, V.M., Barnett, H.L.(1951) Physiology of the Fungi. McGraw-Hill Book Co., 1st edn New York.

[24] Massaccesi, G., Romero, M.C., Cazau, M.C., Bucsinszky, A.M. (2002) Cadmium removal capacities of filamentous soil fungi isolated from industrially polluted sediments, in La Plata (Argentina). World J.Microbiol.Biotechnol, 18: 817 -20 .
[25] Amezcua-Allieri MA, Lead JR, Rodriguez-Vazquez R. (2005) Changes in $\mathrm{Cd}$ and $\mathrm{Cr}$ fluxes during the bioremediation of phenanthrene. Soil Use Manag., 21: $337-9$.

[26] Christian, V., Shrivastava, R., Shukla, D., Modi, H.A., and Vyas BRM (2005) Degradation of xenobiotic compounds by lignin-degradibg white-rot fungi: enzymology and mechanisma involved. Indian J. Experimet.Biol., 43: 301 - 12.

[27] Hestbjerg, H. P. A., Willumsen, M., Christensen, O., Andersen, C. S., Jacobsen.(2003) In-situ depletion of pentachlorophenol from contaminated soil Phanerochaetespp involved in the degradation of environmental pollutants: International Applied and Environ. Microbiol., 56:3093-3100.

[28] Cajthaml, T. M., Moder, P., Kacer, V., Sasek P., Popp, (2002) Study of fungal degradation products of polycyclic aromatic hydrocarbons using gas chromatography with ion trap mass spectrometry detection. J.Chromat. A 974: 213-22.

[29] Levin, L. A. Viale, A. and Forchiassin, (2003) Degradation of organic pollutants by the white rot basidiomycete Trametestrogii. Internat.Biodeterior.Biodegra.52: 1-5. 